\title{
Relationship between Dermal Structural Changes on Ultrasonographic Images and Skin Viscoelasticity in Overweight and Obese Japanese Males
}

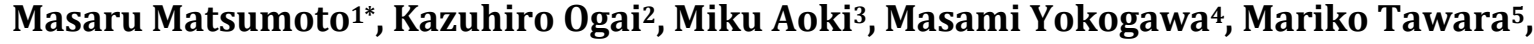 \\ Junko Sugama1,2, Takeo Minematsu'6, Gojiro Nakagami', Misako Dai' ${ }^{1}$, Hiromi Sanada' \\ ${ }^{1}$ Department of Clinical Nursing, School of Health Sciences, College of Medical, Pharmaceutical and Health \\ Sciences, Kanazawa University, Kanazawa, Japan \\ ${ }^{2}$ Wellness Promotion Science Center, Institute of Medical, Pharmaceutical and Health Sciences, Kanazawa \\ University, Kanazawa, Japan \\ ${ }^{3}$ Department of Clinical Nursing, Division of Health Science, Graduate School of Medicine, Kanazawa University, \\ Kanazawa, Japan \\ ${ }^{4}$ Department of Physical Therapy, School of Health Sciences, College of Medical, Pharmaceutical and Health \\ Sciences, Kanazawa University, Kanazawa, Japan \\ ${ }^{5}$ Department of Food and Nutrition, Hokuriku Gakuin University Junior College, Kanazawa, Japan \\ ${ }^{6}$ Department of Gerontological Nursing/Wound Care Management, Graduate School of Medicine, The \\ University of Tokyo, Tokyo, Japan \\ Email: "masaru@staff.kanazawa-u.ac.jp
}

Received 20 February 2016; accepted 5 August 2016; published 8 August 2016

Copyright (C) 2016 by authors and Scientific Research Publishing Inc.

This work is licensed under the Creative Commons Attribution International License (CC BY).

http://creativecommons.org/licenses/by/4.0/

c) (7) Open Access

\section{Abstract}

It has been reported that overweight Japanese males have poorly organised dermis and their skin may be fragile to external forces because of decreased dermal echogenicity. However, it is unknown whether the changes in the dermal structure actually affect the dermal function. The objective of this study was to clarify the relationship between dermal structural parameters and dermal functional parameters in overweight and obese Japanese males. A cross-sectional, observational study was conducted on Japanese male volunteers. Two ultrasound scanners, a $20-\mathrm{MHz}$ Dermascan $\mathrm{C}^{\circledR}$ and an 18-MHz Mylab ${ }^{\mathrm{TM}}$ five ${ }^{\circledR}$ were used to evaluate dermal structure. Echogenicity of the lower dermis and dermal thickness of the participants' abdomens and thighs were measured. A Cutometer ${ }^{\circledR}$ MPA580 was used to evaluate skin viscoelasticity, skin deformation (R0) and elasticity $(\mathrm{R} 2, \mathrm{R} 7)$. The correlation between dermal structural parameters and skin viscoelasticity

\footnotetext{
${ }^{*}$ Corresponding author.

How to cite this paper: Matsumoto, M., Ogai, K., Aoki, M., Yokogawa, M., Tawara, M., Sugama, J., Minematsu, T., Nakagami, G., Dai, M. and Sanada, H. (2016) Relationship between Dermal Structural Changes on Ultrasonographic Images and Skin Viscoelasticity in Overweight and Obese Japanese Males. Health, 8, 1029-1039.
}

http://dx.doi.org/10.4236/health.2016.811106 
were validated using Pearson's correlation coefficient or Spearman's correlation coefficient by rank test. A total of 79 male volunteers were recruited of which 43 were control subjects with BMI $<25$ (age, 22 - 63 years), 25 were overweight subjects with $B M I \geq 25$ to $<30$ (age, 23 - 64 years) and the 11 obese subjects had a BMI $\geq 30$ (age, 26 - 47 years). There was no correlation between dermal structural parameters and skin viscoelasticity in the abdomens or thighs of all 79 participants. On the other hand, in the 36 overweight and obese participants, thigh dermal echogenicity was significantly and negatively correlated with $R 0(r=-0.456, p<0.01)$ and dermal thickness in the abdomen was significantly and positively correlated with $\mathrm{RO}(\mathrm{r}=0.464, \mathrm{p}<0.01)$. The dermal functional parameter was significantly correlated with dermal structural parameters in overweight and obese males; in other words, a decrease in dermal function may be caused by structural changes in the dermis during obesity.

\section{Keywords}

Echogenicity, Japanese Overweight and Obese Males, Skin Viscoelasticity, Dermal Thickness, Skin Physiology/Structure

\section{Introduction}

It has been reported that obese or overweight people have an altered dermal structure compared with normal healthy people. It has also been reported that obese people have a poorly organised dermal collagen structure because of the degradation of collagen fibres, and that these dermal changes are irreversible [1]-[3]. Furthermore, these individuals possess a degraded and diffused collagen matrix compared with normal healthy controls [1]-[3]. Moreover, using ultrasonographic imaging, we have already reported a decrease in dermal echogenicity and an increase in dermal thickness in overweight Japanese males compared with normal healthy controls [4]. We therefore suggest that dermal structural change may take place in overweight and obese people.

The clinical problem is that dermal structural change may cause a decrease in skin function and skin fragility, leaving it vulnerable to insult by external forces. With regard to skin function during obesity, Ibuki et al. reported that obese mice have low tensile strength in the dermal layer of the skin [5]. The dermal layer plays a role in maintaining the mechanical strength of the skin, and a decrease in the dermal tensile strength may be reflected in skin fragility to external forces. Therefore, we believe it is important to clarify the functional role of skin in addition to examining dermal structure in overweight and obese humans.

In overweight or obese individuals there is clearly a decreased effectiveness of the skin as a barrier, but there is no clarity concerning the biomechanical functions of the internal skin, i.e. the dermis. The skin of overweight and obese individuals has higher trans-epidermal water loss (TEWL) compared with normal individuals [6]-[8]. Furthermore, they have a lower water content of the stratum corneum compared with normal individuals [6]. As mentioned above, the skin of overweight and obese individuals has a decreased barrier function, and an alien environmental substance may easily penetrate such skin. On the other hand, few studies have reported on the biomechanical function or mechanical strength of the dermis in overweight or obese individuals.

We suggest that it is necessary to noninvasively measure skin function in overweight or obese individuals, and to do this we focused on skin viscoelasticity, which may clarify the biomechanical functions of the skin. In a previous study, the skin of obese subjects was noted to be similar to "Aging-like skin" because the changes in dermal structure were similar to those observed in aged individuals [9] [10]; structural changes in the dermis were also reported, such as a clear decrease in collagen and elastin fibres [11]. Aging skin has low elastic properties [12]-[14]; therefore, skin elasticity may be decreased by changes in dermal structure.

No previous studies have investigated dermal structure and skin viscoelasticity, or clarified the relationship between dermal structure and skin viscoelasticity in overweight or obese people. Ishikawa et al. reported a lack of relationship between the degree of obesity and skin elasticity [14], but this study did not investigate the body 
site, which is likely to be affected by fat accumulation during obesity. Iizaka et al. [15] reported that the percentage of BMI reduction is associated with the percentage of skin deformation and that this increases in overweight and obese individuals; however, this study only compared skin viscoelasticity before and after weight reduction, and the relationship between BMI and skin viscoelasticity was unknown. Moreover, these previous studies did not investigate the relationship between dermal structure and skin viscoelasticity.

The current study aimed to investigate whether skin function decreased in overweight or obese individuals due to structural changes of the dermis. The objective of this study was to clarify the relationship between the parameters of dermal structure and function.

\section{Methods}

\subsection{Study Design and Setting}

We conducted this cross-sectional observational study from April 2013 to November 2014. All data collection and analyses took place at the campus of the School of Health Science, College of Medical, Pharmaceutical and Health Sciences, Kanazawa University, Japan. All measurement was conducted in the day time, from 9:00 to 18:00. Room temperature and humidity on the ward were controlled to $21^{\circ} \mathrm{C}-25^{\circ} \mathrm{C}$ and $40 \%-60 \%$, respectively.

\subsection{Participants}

The study population included healthy volunteer males with a BMI of $\geq 25 \mathrm{~kg} / \mathrm{m}^{2}$; these individuals consisted of staff members or students of the university, employees of nonfinancial companies and residents around Kanazawa University. We also sought healthy volunteer males with a BMI of $<25 \mathrm{~kg} / \mathrm{m}^{2}$ to act as control subjects. All participants were aged between 20 and 64 years. Exclusion criteria were the presence of a sharp pain or rubor in the body part that would be used for dermal structural measurements or a systemic skin disorder, dry skin, oedema, alcoholism, liver cirrhosis, hepatic insufficiency or renal insufficiency.

\subsection{Measurements and Instruments}

\subsubsection{Measurement of the Dermal Structure}

All measurements of dermal structure and function were performed at the same sites on the abdomen and thigh. We examined the abdomens and thighs as described in our previous study [4]. For the abdomen, we examined the navel circumference while the study participant was in a dorsal recumbent position. For the thigh, we examined the rear side of left thigh while the study participant was in a prone position. All measurement of dermal structure and function were performed by the same investigator.

The 20-MHz Dermascan C ${ }^{\circledR}$ ultrasound scanner (CortexTechnology, Hadsund, Denmark) equipped with software for image analysis was used for the assessment of echogenicity of the dermal structure [16]-[19]. The 20MHz ultrasound transducer allowed for a $60 \times 150 \mu \mathrm{m}$ resolution and a 13-mm penetration depth and the ultrasound velocity for skin was set at $1580 \mathrm{~m} / \mathrm{s}$ [17]. The probe for the longitudinal scan was placed on each site and a total of three photographs were acquired per site in the B-mode. All photographs were taken using fixed values for gain-level 3 and gain-profile-level 10.

The 18-MHz Mylab ${ }^{\mathrm{TM}}$ five ${ }^{\circledR}$ ultrasound scanner (Esaote, Genoa, Italy) was used for the assessment of dermal thickness [4]. For the longitudinal scan, the probe was placed at two sites. The gain was adjusted for each individual, and a photograph was taken. A total of three photographs were acquired per site.

\subsubsection{Measurement of Dermal Function}

The Cutometer MPA $580^{\circledR}$ (Courage + Khazaka, Cologne, Germany) was used to evaluate skin mechanical viscoelasticity parameters [12] [20]-[22]. We used a 2-mm-diameter measuring probe and we applied a constant suction of 500 mbar [13]. The time/strain mode was used with three consecutive cycles of a 2 s suction application followed by a $2 \mathrm{~s}$ relaxation period. We determined the following three parameters [13] [20]. R0 (Uf) was skin deformation (skin length when elongated). R2 (Ua/Uf) was the overall elasticity of the skin including creep and creep recovery (recovery ratio of skin length). R7 (Ur/Uf) was the ratio of elastic recovery to total deformation (ratio of elasticity during constriction). 


\subsubsection{Demographics and Characteristics of the Study Population}

Data collection of the demographics and characteristics of the study population were similar to our previous study [4]. Information on age, sex, anamnesis, oral medication intake and drinking and smoking habits were collected during an oral consultation with each subject. We also measured their height and body weight. We calculated BMI $\left(\mathrm{kg} / \mathrm{m}^{2}\right)$ and body fat ratio (\%) to determine the degree of obesity of each study participant. Bioelectrical impedance analysis was performed using a multi-frequency body composition analyser (MC190; Tanita, Tokyo, Japan) to measure body weight and body fat ratio. We also measured waist circumference diameter using a tape measure; this is an index of visceral fat accumulation. We also interviewed the subjects as to whether they had diabetes, hyperglycemia, hypertension or hyperlipemia, as well as any history of smoking.

\subsection{Image Analysis}

For the evaluation of dermal echogenicity, we used Dermascan $C^{\circledR}$ (CortexTechnology) image analysis software. For each patient we measured the echogenicity of the lower dermis for a similar area of $0.754(0.58 \mathrm{~mm} \times 1.3$ $\mathrm{mm}) \mathrm{mm}^{2}$. We identified the region-of-interests (ROI) at the top of the subcutaneous adipose tissue by superposing a "Shape1 rectangle", from which the "Total intensity in \%" was measured. Total intensity in \% means the average value of the echogenicity ( 0 - 255 range of pixel intensity) of the ROI by percentage as described in our previous study [4]. For the evaluation of dermal thickness, we used the built-in measurement tool Mylab ${ }^{\mathrm{TM}}$ five $^{\circledR}$ (Esaote) as previously described [4]. Dermal thickness was calculated by computing for the average thickness of three areas per image.

\subsection{Statistical Analysis}

All analyses were performed using SPSS for Windows Ver. 22.0. Descriptive data were expressed as the mean \pm standard deviation for continuous variables and " $\mathrm{n}$ " for categorical variables. The correlation between dermal structure parameters and BMI and skin viscoelasticity were validated using Pearson's correlation coefficient or Spearman's correlation coefficient by rank test. The subjects were classified into three groups according to BMI $<25$, $25 \leq \mathrm{BMI}<30$ and $30 \leq \mathrm{BMI}$, representing the normal, overweight and obesity groups, respectively. These three groups were compared using one-way ANOVA followed by the Bonferroni post-tests. Moreover, we determined dermal structure and skin viscoelasticity with dependent variables, and the relationship between dependent variables and independent variables (BMI and age) were calculated using two-way analysis of variance (ANOVA). A p-value of $<0.05$ was considered significant.

\subsection{Ethical Considerations}

This study was approved by the Ethics Committee of the Kanazawa University School of Medicine (\#430). Information obtained from the subjects was not used for any other purpose than the study objective. The subjects were not identified and their privacy was protected. Participation in the study was voluntary, and no disadvantage was incurred by any refusal to participate.

\section{Results}

\subsection{Demographics and Characteristics of the Study Population}

A total of 79 male volunteers were recruited (Table 1). The average age of the 43 control subjects with a BMI < 25 was $38.1 \pm 13.6$ years (range, 22 - 63 years); that of the 25 overweight subjects with BMI $\geq 25$ to $<30$ was $42.7 \pm 12.2$ years (range: 23 - 64 years) and that of the 11 obese subjects with BMI $\geq 30$ was $32.4 \pm 7.3$ years (range: 26 - 47 years). In terms of the basic characteristics of the subjects, the values for body weight, body fat ratio, abdominal circumference and the number of individuals with metabolic syndrome showed significant differences among groups.

\subsection{Dermal Structure in Obese Participants}

There was a significant correlation between dermal structure parameters and BMI. Dermal echogenicity of the 
Table 1. Demographics and characteristics of study population.

\begin{tabular}{|c|c|c|c|c|}
\hline \multirow{2}{*}{ Items } & Control & Overweight & Obesity & \multirow{2}{*}{ p-value } \\
\hline & $\mathrm{BMI}<25(\mathrm{n}=43)$ & $25 \leq \mathrm{BMI}<30(\mathrm{n}=25)$ & $30 \leq$ BMI $(n=11)$ & \\
\hline Age $^{a}$ (years old) & $38.1(13.6)$ & $42.7(12.2)$ & $32.4(7.3)$ & $0.071^{\mathrm{c}}$ \\
\hline Body weight ${ }^{\mathrm{a}}(\mathrm{kg})$ & $65.9(6.6)$ & $80.4(7.8)$ & $92.5(8.9)$ & $0.000^{\mathrm{c}, \mathrm{e}}$ \\
\hline Body fat ratio ${ }^{\mathrm{a}}(\%)$ & $17.2(4.3)$ & $24.4(3.3)$ & $30.6(4.0)$ & $0.000^{\mathrm{c}, \mathrm{e}}$ \\
\hline Abdominal circumference $(\mathrm{cm})$ & $81.9(6.0)$ & $94.0(5.5)$ & $104.4(6.6)$ & $0.000^{c, e}$ \\
\hline Hyper tension $^{\mathrm{b}}(\mathrm{n})$ & $3(7.0)$ & $4(16.0)$ & $4(36.4)$ & $0.044^{\mathrm{d}}$ \\
\hline Hyperlipemia $^{\mathrm{b}}(\mathrm{n})$ & $6(14.0)$ & $5(20.0)$ & $3(27.3)$ & $0.458^{\mathrm{d}}$ \\
\hline Diabetes mellitus $^{\mathrm{b}}$ (n) & $0(0.0)$ & $2(8.0)$ & $1(9.0)$ & $0.121^{\mathrm{d}}$ \\
\hline Metabolic syndrome ${ }^{\mathrm{b}}$ (n) & $1(2.3)$ & $4(16.0)$ & $3(27.3)$ & $0.016^{\mathrm{d}}$ \\
\hline Smoking $^{\mathrm{b}}(\mathrm{n})$ & $11(25.6)$ & $7(28.0)$ & $4(36.4)$ & $0.475^{\mathrm{d}}$ \\
\hline
\end{tabular}

${ }^{a}$ Mean value (SD), ${ }^{b}$ number of subjects (\%), ${ }^{\mathrm{c} O n e-w a y ~ A N O V A, ~}{ }^{\mathrm{d}}$ Fisher's exact test, ${ }^{\mathrm{e}}$ Multiple comparison (significant difference between all groups).

abdomen was significantly and negatively correlated with BMI $(r=-0.388, p<0.01)$. Dermal thickness of the abdomen was significantly and positively correlated with BMI $(r=0.448, p<0.01)$. Dermal echogenicity of the thigh was significantly and negatively correlated with BMI $(r=-0.659, p<0.01)$. Dermal thickness of the thigh was significantly and positively correlated with BMI $(r=0.681, p<0.01)$. The results of multiple comparisons showed that the obesity group exhibited a significantly thicker abdominal dermis than the normal group, and normal and overweight group for the thigh. Moreover, the obesity group showed a significantly lower dermal echogenicity than the normal and overweight groups for the abdomen, and the normal group for the thigh ( $\mathrm{p}<0.01$, respectively) (Figure 1). Figure 2 shows typical structure of dermis in ultrasonographic images by the $20 \mathrm{MHz}$ ultrasound scanner of normal, overweight and obese subject in abdomen and thigh.

\subsection{Correlations between Dermal Structure and Skin Viscoelasticity}

There was no correlation between the parameters of dermal structure and skin viscoelasticity in the abdomens and thighs of all 79 participants including persons with normal BMI (Table 2). On the other hand, in 36 overweight and obese participants, dermal echogenicity of the thigh was significantly and negatively correlated with R0 and dermal thickness of the abdomen was significantly and positively correlated with R0. There was no significant correlation between R2 and R7 (Table 3).

\subsection{Relations between Dermal Structure, BMI and Age}

From the results of two-way ANOVA, a main effect was found between the parameters of dermal structure, dermal thickness $(\mathrm{p}<0.001)$ and dermal echogenicity $(\mathrm{p}=0.004)$, and BMI in abdomen; a main effect was found between the parameters of dermal structure, dermal thickness $(\mathrm{p}<0.001)$ and dermal echogenicity $(\mathrm{p}<$ 0.001), and BMI in thigh. However, no main effect was found between dermal structural parameters and age. Also, no interaction was found between BMI and age (Table 4).

\subsection{Relations between Skin Viscoelasticity, BMI and Age}

From the results of two-way ANOVA, a main effect was found between the parameters of skin viscoelasticity, R2 ( $\mathrm{p}=0.004)$ and R7 ( $<0.001)$, and age in abdomen; a main effect was found between the parameters of skin viscoelasticity, R0 ( $p=0.015)$, R2 ( $p<0.001)$ and R7 ( $<0.001)$, and age in the thigh. However, no main effect was found between the parameters of skin viscoelasticity and BMI and no interaction was found between BMI and age (Table 5). 
Dermal thickness

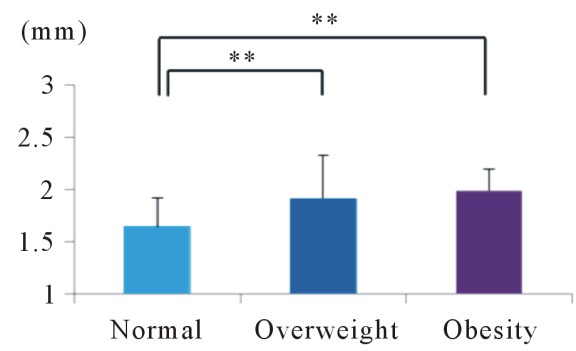

(A)

Dermal thickness

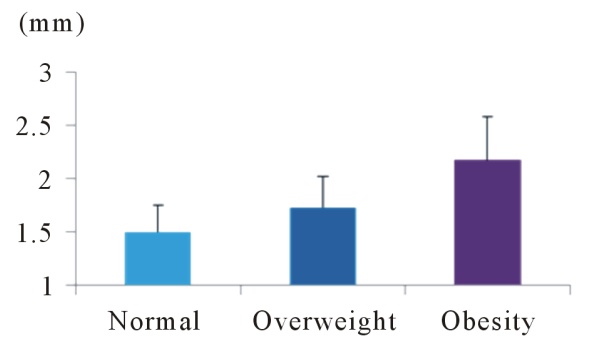

(C)
Dermal echogenicity

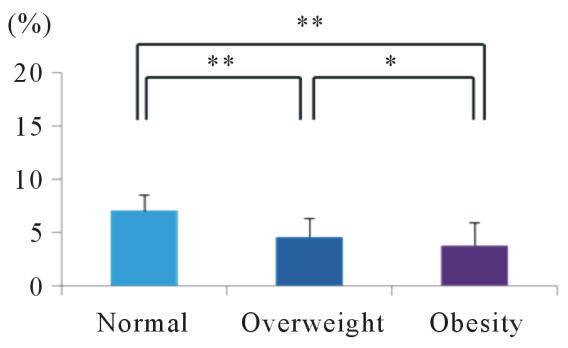

(B)

Dermal echogenicity

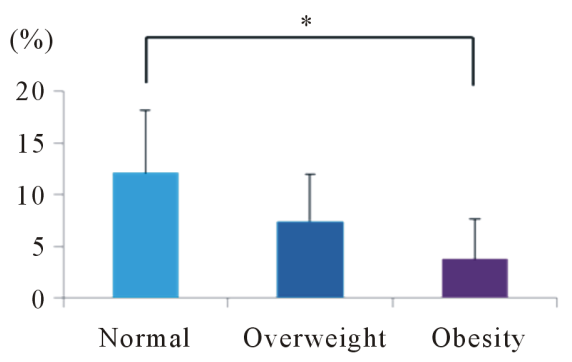

(D)

Figure 1. Dermal thickness and echogenicity in three groups. (A) Dermal thickness in abdomen; (B) dermal echogenicity in abdomen; (C) dermal thickness in thigh; (D) dermal echogenicity in thigh. Statistical significance was taken as $\mathrm{p}<0.05$. A p-value was expressed as: ${ }^{*} \mathrm{p}<0.05$ and $* * \mathrm{p}<0.01$.

(e)
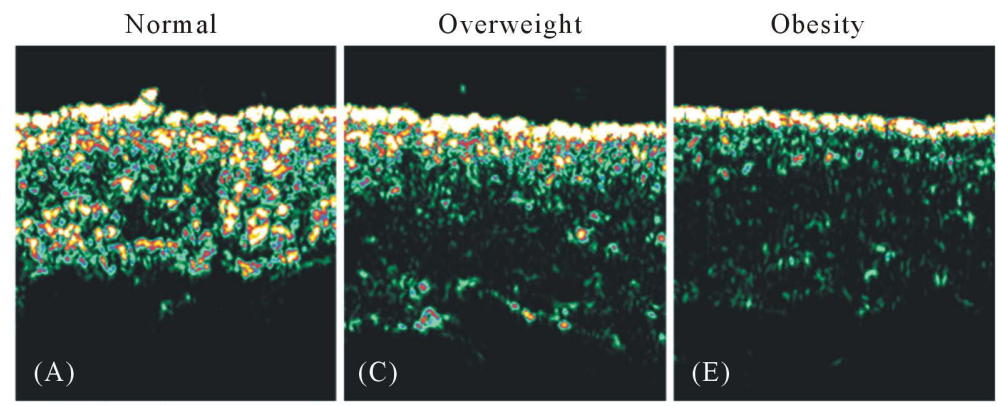

Abdomen

(e)
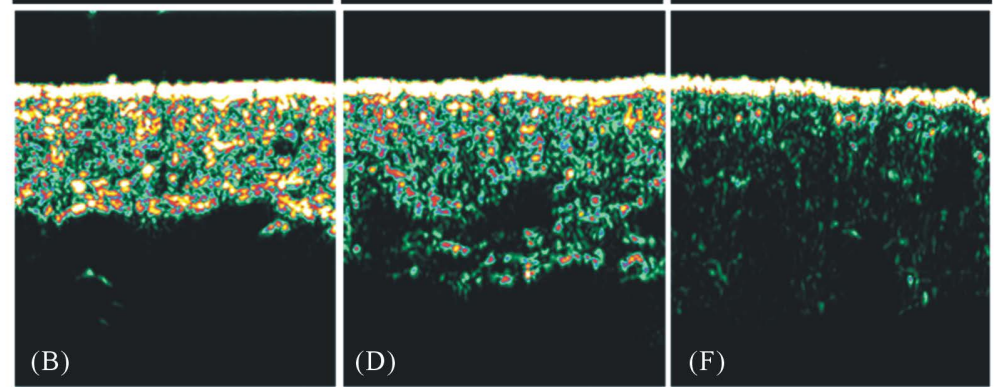

Thigh

Figure 2. Typical structure of dermis in ultrasonographic images by the $20 \mathrm{MHz}$ ultrasound scanner of normal, overweight and obese subject in abdomen and thigh. In two parts, echogenicity decreased in the lower dermis in an overweight and obese person. (A) (B) A normal subject; 20s male, BMI of 22.6. (C) (D) An overweight subject; 20s male, BMI of 27.6. (E) (F) An obese subject; 20 s male, BMI of 36.4. (A) Echogenicity of lower dermis; 16.9\%. (B) Echogenicity of lower dermis; 26.4\%. (C) Echogenicity of lower dermis; 2.9\%. (D) Echogenicity of lower dermis; 6.6\%. (E) Echogenicity of lower dermis; 2.1\%. (F) Echogenicity of lower dermis; 2.5\%. (e) Epidermis. (d) Dermis. (s) Subcutaneous adipose tissue. 
Table 2. The correlation coefficient between the parameters of dermal structure and skin viscoelasticity in all participants $(n=79)$.

\begin{tabular}{ccccc}
\hline \multirow{2}{*}{ Dermal structure } & Body site & \multicolumn{3}{c}{ Skin viscoelasticity } \\
\cline { 3 - 5 } & & $\mathrm{R} 0$ & $\mathrm{R} 2$ & $\mathrm{R} 7$ \\
\hline \multirow{2}{*}{ Dermal echogenicity } & Abdomen & -0.049 & 0.010 & 0.034 \\
& Thigh & -0.181 & 0.146 & -0.215 \\
Dermal thickness & Abdomen & 0.217 & 0.045 & -0.006 \\
& Thigh & 0.180 & -0.164 & 0.161 \\
\hline
\end{tabular}

Table 3. The correlation coefficient between the parameters of dermal structure and skin viscoelasticity in overweight and obese participants $(n=36)$.

\begin{tabular}{ccccc}
\hline & & \multicolumn{3}{c}{ Skin viscoelasticity } \\
\cline { 3 - 4 } Dermal structure & Body site & R0 & R2 & R7 \\
\cline { 3 - 4 } Dermal echogenicity & Abdomen & -0.212 & -0.046 & -0.053 \\
& Thigh & $-0.456^{*}$ & 0.197 & 0.239 \\
Abdomen & $0.464^{*}$ & 0.067 & 0.114 \\
\hline
\end{tabular}

*Statistically significant relationship $(\mathrm{p}<0.01)$.

Table 4. Relationship between dermal structure and BMI, age.

Abdomen

\begin{tabular}{ccccccc}
\hline \multirow{2}{*}{ Variables } & \multicolumn{3}{c}{ Dermal thickness } & \multicolumn{3}{c}{ Dermal echogenicity } \\
\cline { 2 - 7 } & $\begin{array}{c}\text { Degrees of } \\
\text { freedom }\end{array}$ & F & P-value & $\begin{array}{c}\text { Degrees of } \\
\text { freedom }\end{array}$ & F & p-value \\
\hline BMI & 2 & 9.127 & $<0.001$ & 2 & 6.118 & 0.004 \\
Age & 4 & 2.115 & 0.090 & 4 & 0.416 & 0.796 \\
BMI, Age & 6 & 2.072 & 0.070 & 6 & 11.448 & 0.566 \\
\hline
\end{tabular}

Thigh

\begin{tabular}{ccccccc}
\hline & \multicolumn{3}{c}{ Dermal thickness } & \multicolumn{3}{c}{ Dermal echogenicity } \\
\cline { 2 - 7 } Variables & $\begin{array}{c}\text { Degrees of } \\
\text { freedom }\end{array}$ & F & P-value & $\begin{array}{c}\text { Degrees of } \\
\text { freedom }\end{array}$ & F & p-value \\
\hline BMI & 2 & 24.291 & $<0.001$ & 2 & 14.194 & $<0.001$ \\
Age & 4 & 0.687 & 0.604 & 4 & 0.603 & 0.662 \\
BMI, Age & 6 & 1.985 & 0.082 & 6 & 1.940 & 0.088 \\
\hline
\end{tabular}


Table 5. Relationship between skin elasticity and BMI, age.

\begin{tabular}{|c|c|c|c|c|c|c|c|c|c|}
\hline \multirow{2}{*}{ Variables } & \multicolumn{3}{|c|}{ R0 } & \multicolumn{3}{|c|}{ R2 } & \multicolumn{3}{|c|}{ R7 } \\
\hline & $\begin{array}{l}\text { Degrees of } \\
\text { freedom }\end{array}$ & $\mathrm{F}$ & P-value & $\begin{array}{l}\text { Degrees of } \\
\text { freedom }\end{array}$ & $\mathrm{F}$ & P-value & $\begin{array}{l}\text { Degrees of } \\
\text { freedom }\end{array}$ & F & $\mathrm{p}$-value \\
\hline BMI & 2 & 2.543 & 0.089 & 2 & 1.071 & 0.349 & 2 & 1.865 & 0.163 \\
\hline Age & 4 & 2.384 & 0.060 & 4 & 4.193 & 0.004 & 4 & 6.437 & $<0.001$ \\
\hline BMI, Age & 6 & 0.780 & 0.589 & 6 & 0.273 & 0.948 & 6 & 0.602 & 0.728 \\
\hline
\end{tabular}

\begin{tabular}{|c|c|c|c|c|c|c|c|c|c|}
\hline Thigh & & & & & & & & & \\
\hline \multirow{2}{*}{ Variables } & \multicolumn{3}{|c|}{ R0 } & \multicolumn{3}{|c|}{ R2 } & \multicolumn{3}{|c|}{ R7 } \\
\hline & $\begin{array}{l}\text { Degrees of } \\
\text { freedom }\end{array}$ & $\mathrm{F}$ & P-value & $\begin{array}{l}\text { Degrees of } \\
\text { freedom }\end{array}$ & F & P-value & $\begin{array}{l}\text { Degrees of } \\
\text { freedom }\end{array}$ & F & p-value \\
\hline BMI & 2 & 1.232 & 0.299 & 2 & 0.450 & 0.639 & 2 & 0.350 & 0.706 \\
\hline Age & 4 & 3.331 & 0.015 & 4 & 6.845 & $<0.001$ & 4 & 7.242 & $<0.001$ \\
\hline BMI, Age & 6 & 1.514 & 0.188 & 6 & 0.513 & 0.796 & 6 & 0.795 & 0.577 \\
\hline
\end{tabular}

\section{Discussion}

The current study investigated dermal structure and skin viscoelasticity in overweight and obese Japanese males. The study was novel, in that we clarified that dermal echogenicity was decreased and dermal thickness was significantly increased in obese subjects. Moreover, we clarified the parameters of skin deformation that were significantly correlated with dermal echogenicity and dermal thickness in overweight and obese males.

An increased degree of obesity may increase dermal thickness and may decrease dermal echogenicity; furthermore, changes in dermal structure may be reflected in histological changes in the dermis. This study showed a significant difference in dermal structural parameters between overweight and obese males, and also showed a significant correlation between BMI and these parameters. To our knowledge, this is the first study to show quantitative data on dermal structure in obese individuals; whereas a previous study [23] has shown similar findings using qualitative data. Furthermore, in obese people, a diffusion or decrease of collagen fibres [1]-[3] and elastin fibres [24] has been reported in the dermal layer. A decrease of dermal echogenicity is known to be common with skin aging [25], and the decreasing density of collagen or elastin fibres may influence the decrease in dermal echogenicity. However, it has been reported that aging skin has a thinner dermis [26], and the increase in dermal thickness found in the current study was different from the results of aging skin. Therefore, the skin of obese males may have different histological characteristics from aging skin.

We believe that dermal function is decreased by the change of dermal structure in overweight or obese subjects because this study showed a significant correlation between the dermal structure parameters and skin viscoelasticity. In previous studies, structural changes of the dermis and a decrease in parameters of skin viscoelasticity due to aging have been shown [12] [13] [25] [26]. On the other hand, a previous study investigated relations between dermal structure and function and showed that the depth of dermal anchoring structure was significantly and positively correlated with the R7 parameter (skin elasticity) [27]. In addition, the loss of intact dermal collagen fibre bundles was significantly and positively correlated with a decrease of R0 parameter (skin deformation) [28]. Moreover, the R0 parameter addresses the maximum amplitude and represents the passive behaviour of the skin to force (firmness). An increase of the R0 parameter in skin with a low echogenicity or thick dermis may also be associated with an abnormal softness of the skin.

This present study revealed a correlation between dermal structure and skin mechanical properties and indicated that a change of dermal structure due to obesity may cause a decrease in dermal function. The main function of the dermis is to buffer the impact of external forces on the body, and it may be effective in preventing 
external forces from causing damage to the skin of overweight and obese patients in a clinical setting. In addition, the parameter of skin viscoelasticity, which we used in this study, may be important in developing new skin care practices for obese individuals in the future.

This study had some limitations. Although racial and sex differences have been noted in dermal structure [29]-[31], this present study only produced results for Japanese males. Furthermore, we did not evaluate skin hydration in this study. It has been reported that high frequency ultrasound is effective in predicting skin hydration. For example, it has been reported that dermal echogenicity is decreased in dry facial skin and skin oedema [32] [33]. Since we did not include subjects with dry skin or skin oedema in the present study, we suggest that the influence of echogenicity on skin hydration is minimal. As the skin viscoelasticity measurements were limited to just $2 \mathrm{~mm}$ probe $\left(\right.$ Cutometer $^{\circledR}$ ), the measurements may not represent the skin elasticity of the whole area but also the area from epidermis to upper dermis.

\section{Conclusion}

Decreased dermal echogenicity and increased dermal thickness in ultrasonographic images were significantly correlated with the degree of obesity. Dermal functional parameters were significantly correlated with dermal structural parameters in overweight and obese males, which suggested that a decrease of dermal function may be caused by structural changes of the dermis during obesity.

\section{Acknowledgements}

The authors would like to thank all participants who took part in this study.

\section{Funding Statement}

This study was partly supported by grants from the Japan Nursing School Association, JSPS KAKENHI Grant Number 26293444 (Grant-in-Aid for Scientific Research B for JS) and Grant Number 15K20665 (Grant-in-Aid for Young Scientists B for MM).

\section{References}

[1] Light, D., Arvanitis, G.M., Abramson, D. and Glasberg, S.B. (2010) Effect of Weight Loss after Bariatric Surgery on Skin and the Extracellular Matrix. Plastic and Reconstructive Surgery, 125, 345-351. http://dx.doi.org/10.1097/PRS.0b013e3181c2a657

[2] Orpheu, S.C., Coltro, P.S., Scopel, G.P., Gomez, D.S., Rodrigues, C.J., Modolin, M.L., Faintuch, J., Gem Perli, R. and Ferreira, M.C. (2010) Collagen and Elastic Content of Abdominal Skin after Surgical Weight Loss. Obesity Surgery, 20, 480-486. http://dx.doi.org/10.1007/s11695-009-0019-0

[3] Fearmonti, R.M., Blanton, M., Bond, J.E., Pestana, I.A., Selim, M. and Erdmann, D. (2012) Changes in Dermal Histomorphology Following Surgical Weight Loss versus Diet-Induced Weight Loss in the Morbidly Obese Patient. Annals of Plastic Surgery, 68, 507-512. http://dx.doi.org/10.1097/SAP.0b013e31823aefc3

[4] Matsumoto, M., Ibuki, A., Minematsu, T., Sugama, J., Horii, M., Ogai, K., Nishizawa, T., Dai, M., Sato, A., Fujimoto, Y., Okuwa, M., Nakagami, G., Nakatani, T. and Sanada, H. (2014) Structural Changes in Dermal Collagen and Oxidative Stress Levels in the Skin of Japanese Overweight Males. International Journal of Cosmetic Science, 36, 477-484. http://dx.doi.org/10.1111/ics.12145

[5] Ibuki, A., Akase, T., Nagase, T., Minematsu, T., Nakagami, G., Horii, M., Sagara, H., Komeda, T., Koba Yashi, M., Shimada, T., Aburada, M., Yoshimura, K., Sugama, J. and Sanada, H. (2012) Skin Fragility in Obese Diabetic Mice: Possible Involvement of Elevated Oxidative Stress and Upregulation of Matrix Metalloproteinases. Experimental Dermatology, 21, 178-183. http://dx.doi.org/10.1111/j.1600-0625.2011.01409.X

[6] Sugama, J., Shigeta, Y., Fukuda, S., Matsuo, J., Kitagawa, A., Konya, C., Murasawa, E., Seto, M., Okada, M. and Matsuoka, N. (2011) Skin Physiology and Skin Manifestations and Relationship to Degree of Obesity in Japanese Subjects Aged between 20 and 59 Years. Journal of Society of Nursing Practice, 23, 24-29. (In Japanese)

[7] Guida, B., Nino, M., Perrino, N.R., Laccetti, R., Trio, R., Labella, S. and Balato, N. (2010) The Impact of Obesity on Skin Disease and Epidermal Permeability Barrier Status. Journal of the European Academy of Dermatology and Venereology, 24, 191-195. http://dx.doi.org/10.1111/j.1468-3083.2009.03503.x

[8] Löffler, H., Aramaki, J.U. and Effendy, I. (2002) The Influence of Body Mass Index on Skin Susceptibility to Sodium Lauryl Sulphate. Skin Research and Technology, 8, 19-22. http://dx.doi.org/10.1046/j.0909-752x 
[9] Akase, T., Nagase, T., Huang, L., Ibuki, A., Minematsu, T., Nakagami, G., Ohta, Y., Shimada, T., Aburada, M., Sugama, J. and Sanada, H. (2012) Aging Like Skin Changes Induced by Ultraviolet Irradiation in an Animal Model of Metabolic Syndrome. Biological Research for Nursing, 14, 180-187. http://dx.doi.org/10.1177/1099800411401013

[10] Nagase, T., Akase, T., Sanada, H., Minematsu, T., Ibuki, A., Huang, L., Asada, M., Yoshimura, K., Nagase, M., Shimada, T., Aburada, M., Nakagami, G. and Sugama, J. (2013) Aging-Like Skin Changes in Metabolic Syndrome Model Mice Are Mediated by Mineralocorticoid Receptor Signaling. Aging Cell, 12, 50-57. http://dx.doi.org/10.1111/acel.12017

[11] Uitto, J. (1989) Connective Tissue Biochemistry of the Aging Dermis. Age-Associated Alterations in Collagen and Elastin. Clinics in Geriatric Medicine, 5, 127-147. http://www.ncbi.nlm.nih.gov/pubmed/2645992

[12] Luebberding, S., Krueger, N. and Kerscher, M. (2014) Mechanical Properties of Human Skin in Vivo: A Comparative Evaluation in 300 Men and Women. Skin Research and Technology, 20, 127-135. http://dx.doi.org/10.1111/srt.12094

[13] Ryu, H.S., Joo, Y.H., Kim, S.O., Park, K.C. and Youn, SW. (2008) Influence of Age and Regional Differences on Skin Elasticity as Measured by the Cutometer. Skin Research and Technology, 14, 354-358. http://dx.doi.org/10.1111/j.1600-0846.2008.00302.x

[14] Ishikawa, T., Ishkikawa, O. and Miyachi, T. (1995) Measurement of Skin Elastic Properties with a New Suction Device (I): Relationship to Age, Sex and the Degree of Obesity in Normal Individuals. The Journal of Dermatology, 22, 713-717. http://dx.doi.org/10.1111/j.1346-8138.1995.tb03907.x

[15] Izaka, S., Minematsu, T., Oba, M., Akase, T., Sanada, H. and Sugama, J. (2010) Skin Function in Overweight Individuals and the Effect of Weight Reduction. Journal of Japanese Society of Wound, Ostomy and Continence Management, 14, 258-265. (In Japanese)

[16] Rosenbaum, M., Prieto, V., Hellmer, J., Boschmann, M., Krueger, J., Leibel, R.L. and Ship, A.G. (1998) An Exploratory Investigation of the Morphology and Biochemistry of Cellulite. Plastic \& Reconstructive Surgery, 101, 1934-1939. http://www.ncbi.nlm.nih.gov/pubmed/?term=An+exploratory+investigation+of+the+morphology+and+biochemistry+o $\underline{\mathrm{f}+\text { cellulite }}$ http://dx.doi.org/10.1097/00006534-199806000-00025

[17] Polanska, A., Danczak-Pazdrowska, A., Silny, W., Woźniak, A., Maksin, K., Jenerowicz, D. and Janicka-Jedyńska, M. (2013) Comparison between High Frequency Ultrasonography (Dermascan C, Version 3) and Histopathology in Atopic Dermatitis. Skin Research and Technology, 19, 432-437. http://dx.doi.org/10.1111/srt.12064

[18] Kim, H., Koh, J., Beak, J., Seo, Y., Kim, B., Kim, J., Lee, J., Ryoo, H. and Jung, H. (2011) Retinyl Retinoate, a Novel Hybrid Vitamin Derivative, Improves Photoaged Skin: A Double-Blind, Randomized-Controlled Trial. Skin Research and Technology, 17, 380-385. http://dx.doi.org/10.1111/j.1600-0846.2011.00512.x

[19] Christ, C., Brenke, R., Sattler, G., Siems, W., Novak, P. and Daser, A. (2008) Improvement in Skin Elasticity in the Treatment of Cellulite and Connective Tissue Weakness by Means of Extracorporeal Pulse Activation Therapy. Aesthetic Surgery Journal, 28, 538-544. http://dx.doi.org/10.1016/j.asj.2008.07.011

[20] Ezure, T. and Amano, S. (2010) Influence of Subcutaneous Adipose Tissue Mass on Dermal Elasticity and Sagging Severity in Lower Cheek. Skin Research and Technology, 16, 332-338. http://dx.doi.org/10.1111/j.1600-0846.2010.00438.x

[21] Piérard, G.E., Hermanns-Lê, T., Paquet, P. and Piérard-Franchimont, C. (2014) Skin Viscoelasticity during Hormone Replacement Therapy for Climacteric Ageing. International Journal of Cosmetic Science, 36, 88-92. http://dx.doi.org/10.1111/ics.12100

[22] Matsumoto, M., Matsuo, J., Dai, M., Nishizawa, T., Matsui, K., Ichikawa, Y., Okuwa, M., Sugama, J., Sanada, H., et al. (2014) Influence of Differences in Washing Methods on Skin Texture. International Journal of Cosmetic Science, 36, 175-181. http://dx.doi.org/10.1111/ics.12114

[23] Horii, M., Sugama, J., Oe, M., Minematsu, T., Nagase, T., Yabunaka, K., Akase, T., Nakagami, G., Ibuki, A. and Sanada, H. (2012) Ultrasonography Reveals Structural Changes in the Dermis and Subcutaneous Tissue of Obese Males: Investigation of the Association with Oxidative Stress. Journal of Japanese Society of Wound, Ostomy and Continence Management, 17, 23-32. (In Japanese)

[24] Ezure, T. and Amano, S. (2015) Increment of Subcutaneous Adipose Tissue Is Associated with Decrease of Elastic Fibers in the Dermal Layer. Experimental Dermatology, 24, 924-929. http://dx.doi.org/10.1111/exd.12816

[25] Gniadecka, M. and Jemec, G.B. (1998) Quantitative Evaluation of Chronological Ageing and Photoageing in Vivo: Studies on Skin Echogenicity and Thickness. British Journal of Dermatology, 139, 815-821. http://dx.doi.org/10.1046/j.1365-2133.1998.02506.x

[26] Branchet, M.C., Boisnic, S., Frances, C. and Robert, A.M. (1990) Skin Thickness Changes in Normal Aging Skin. Gerontology, 36, 28-35. http://www.ncbi.nlm.nih.gov/pubmed/2384222 http://dx.doi.org/10.1159/000213172 
[27] Ezure. T., Yagi, E., Amano, S. and Matsuzaki, K. (2016) Dermal Anchoring Structures: Convex Matrix Structures at the Bottom of the Dermal Layer That Contribute to the Maintenance of Facial Skin Morphology. Skin Research and Technology, 22, 152-157.

[28] Nishimori, Y., Edwards, C., Pearse, A., Matsumoto, K., Kawai, M. and Marks, R. (2001) Degenerative Alterations of Dermal Collagen Fiber Bundles in Photodamaged Human Skin and UV-Irradiated Hairless Mouse Skin: Possible Effect on Decreasing Skin Mechanical Properties and Appearance of Wrinkles. Journal of Investigative Dermatology, 117, 1458-1463. http://dx.doi.org/10.1038/jid.2001.2

[29] Griffiths, G.E.M., Wang, T.S., Hamilton, T.A., Voorhees, J.J. and Ellis, C.N. (1992) A Photonumeric Scale for the Assessment of Cutaneous Photodamage. Archives of Dermatology, 128, 347-351. http://dx.doi.org/10.1001/archderm.1992.01680130061006

[30] Querleux, B., Baldeweck, T., Diridollow, S., de Rigal, J., Huguet, E., Leroy, F. and Barbosa, V.H. (2009) Skin from Various Ethnic Origins and Aging: An in Vivo Cross-Sectional Multimodality Imaging Study. Skin Research and Technology, 15, 306-313. http://dx.doi.org/10.1111/j.1600-0846.2009.00365.x

[31] Giacomoni, P.U., Mammone, T. and Teri, M. (2009) Gender-Linked Differences in Human Skin. Journal of Dermatological Science, 55, 144-149. http://dx.doi.org/10.1016/j.jdermsci.2009.06.001

[32] Mlosek, R.K., Malinowska, S., Sikora, M., Dębowska, R., Stępień, A., Czekaj, K. and Dąbrowska, A. (2013) The Use of High Frequency Ultrasound Imaging in Skin Moisturization Measurement. Skin Research and Technology, 19, 169175. http://dx.doi.org/10.1111/srt.12029

[33] Gniadecka, M. and Quistorff, B. (1996) Assessment of Dermal Water by High-Frequency Ultrasound: Comparative Studies with Nuclear Magnetic Resonance. British Journal of Dermatology, 135, 218-224. http://dx.doi.org/10.1111/j.1365-2133.1996.tb01150.x

\section{Submit or recommend next manuscript to SCIRP and we will provide best service for you:}

Accepting pre-submission inquiries through Email, Facebook, Linkedin, Twitter, etc A wide selection of journals (inclusive of 9 subjects, more than 200 journals)

Providing a 24-hour high-quality service

User-friendly online submission system

Fair and swift peer-review system

Efficient typesetting and proofreading procedure

Display of the result of downloads and visits, as well as the number of cited articles

Maximum dissemination of your research work

Submit your manuscript at: http://papersubmission.scirp.org/ 